\title{
Analysis of the potential of cupuaçu husks (Theobroma grandiflorum) as raw material for the synthesis of bioproducts and energy generation
}

\author{
Nicole MARASCA ${ }^{1}$, Mateus Rodrigues BRITO ${ }^{1}$, Michele Cristine Diel RAMBO ${ }^{2}$, Cristiane PEDRAZZI ${ }^{3}$, \\ Elisandra SCAPIN ${ }^{1,4 *}$ (D), Magale Karine Diel RAMBO ${ }^{1}$
}

\begin{abstract}
Lignocellulosic waste is a valuable source of energy, fuels, and raw materials for the chemical industry. In this study, the potential of cupuaçu husks, derivative from a typical fruit of the Brazilian Amazon, was evaluated. Therefore, biomass was submitted to acid hydrolysis and pyrolysis, and the contents of sugars, by-products, bio-oil compounds, and bio-oil theoretical energy potential were determined. X-ray diffraction, High performance liquid chromatography, Fourier-transform infrared and Gas chromatography mass spectrometry analyzes were used. The hydrolysate has considerable sugar levels (31.7\%) and presence of relevant by-products including furfural, levulinic acid and hydroxymethylfurfural. Bio-oil contained a variety of phenolic compounds, and its theoretical energy potential suggested usability of cupuaçu husks for energy generation. Economic analysis showed that commercialization of bioproducts obtained by biomass hydrolysis and pyrolysis could be highly profitable. These outcomes indicate a range of applications for cupuaçu husks in biorefinery processes and potential to promote sustainability and social development.
\end{abstract}

Keywords: cupuaçu husks; acid hydrolysis; pyrolysis; bio-oil; bioproducts.

Practical Application: This work aims to analyze the use of cupuaçu husks, agroresidual biomass increasingly produced in Brazil, in biorefinery processes, as in the synthesis of bioproducts and energy generation. This article emphasizes the use of this Brazilian agroresidue for production of high value-added compounds and generation of clean energy, both extremely necessary products in the current world perspective of financial, and socio-environmental development.

\section{Introduction}

The use of lignocellulosic biomass in the chemical industry is based on the need to diversify renewable energy sources while ensuring socioeconomic and environmental sustainability (Mendes \& Barros, 2021; Takkellapati et al., 2018). Lignocellulosic materials derived from residual supplies are an attractive biomass source due to their abundance in communities of local producers (Sharma et al., 2019). These individuals might profit from the excess waste to improve their standard of living and contribute to environmental sustainability (Mendes \& Barros, 2021).

Cupuaçu (Theobroma grandiflorum) is an Amazonian fruit native produced and collected in several states in northern Brazil. The main residue of this growing popularity fruit, cupuaçu husks, is a potential lignocellulosic source in the synthesis of bioproducts through processes known as acid hydrolysis and pyrolysis (Golveia et al., 2018).

The process of acid hydrolysis of the main biomass components (cellulose and hemicellulose) enables the extraction of monomers used in the production of high-value biofuels and chemicals such as Furfural (FF), Levulinic Acid (LA) and 5-Hydroxymethylfurfural (HMF). These compounds have a wide range of chemistry applications, including subsequent conversion into others products of interest (Mukherjee et al., 2015; Yan et al., 2014).

The process of pyrolysis thermally degrades the biomass and generates the bio-oil, a liquid mixture of various organic compounds that may be used as a raw material for chemical products or converted into biofuels (Krause et al., 2019; Gunawan et al., 2013). The characterization of biomass and the identification of bio-oil elements are important to establishing the economic viability of the process, which will indicate whether the technique can be employed in biorefinery processes (Dang et al., 2016). In addition, many researches assess the potential of bio-oil as a fuel and in energy generation processes, especially in face of the need for new energy sources motivated by the actual deteriorating environmental conditions. (Kawale \& Kishore, 2019; Milian-Luperón et al., 2020).

The current perspective of the integral use of residues in biorefineries, such as local agroresidues, has emphasized the integration of different processes, or technological routes, aiming at the generation of several resources such as energy, biofuels and value-added products (Mohammad et al., 2019). Based on this fact, the objective of the present research was to evaluate the 
use of cupuaçu husks as a source of furanic compounds applying acid hydrolysis, as well as through pyrolysis process, explore the bio-oil production and its respective energy generation potential, in search of socio-economic and environmental development under the biorefinery concept.

\section{Materials and method}

\subsection{Cupuaçu husks obtainment}

The cupuaçu husks were donated by a rural property located in the region of Bom Jardim-MA, Brazil. They were oven dried at $60^{\circ}$ C (SolidSteel SSD 110L, Piracicaba, Brazil) for 24 hours to remove residual moisture. The material was then crushed in a knife mill (Start FT 50, Fortinox, Piracicaba, Brazil), sieved in 22 mesh until it reached an average thickness of $515 \mu \mathrm{m}$ (Supplementary Figure S1), and was then stored in airtight flasks for further analyzes.

\subsection{Extractives}

The content of extracts was determined in accordance with the National Renewable Energy Laboratory (National Renewable Energy Laboratory, 2008) using a Soxhlet extractor during 16 hours.

\subsection{Ash content}

The ash content was determined using $1 \mathrm{~g}$ of raw biomass in a muffle (1200 DRP7, SP Labor, Presidente Prudente, Brazil) at a temperature of $600 \pm 50^{\circ} \mathrm{C}$ for approximately 4 hours (American Society for Testing and Materials, 2018).

\subsection{Lignin content}

The quantification of acid soluble lignin (ASL) and acid insoluble lignin (AIL) was performed according to the NREL methodology (National Renewable Energy Laboratory, 2012). The total lignin (TL) content was obtained by summing the levels of ASL and AIL.

\subsection{Holocellulose content}

The hemicellulosic fraction present in the raw biomass was obtained by the difference between the Neutral Detergent Fiber (NDF) and Acid Detergent Fiber (ADF) of the material, as determined by the Association of Official Analytical Chemists (1995). The cellulose was quantified by the difference between the NDF, hemicellulose and lignin values (Ding et al., 2012).

\subsection{Crystallinity}

Cupuaçu husks were dried at $80^{\circ} \mathrm{C}$ and their crystallinity measured using X-ray diffraction analysis in an X-ray diffractometer (Bruker D8 Advance, Karlsruhe, Germany) with CuKa radiation at $20 \mathrm{mV}$, diffraction angle $2 \theta$ from 5 to $35^{\circ}$ in steps of $0.05^{\circ}$. The crystallinity index (CrI) was determined according to Segal et al. (1959).

\subsection{Acid hydrolysis}

A single acid hydrolysis step was used to determine the content of glucose, xylose, arabinose and high value-added by- products (FF, LA and HMF) in the cupuaçu husks according to the optimized methodology of Dunning \& Dallas (1949). The volume of $10 \mathrm{~mL}$ of $72 \%$ sulfuric acid was added (Hexis, Jundiaí, Brazil) into $2 \mathrm{~g}$ of biomass and then placed the material in a thermal bath (SolidSteel SSD 5L, Piracicaba, Brazil) at $50^{\circ} \mathrm{C}$ for 7 minutes with constant agitation. Afterwards, $50 \mathrm{~mL}$ of distilled water was added to the content, and placed in an autoclave (Phoenix, Araraquara, Brazil) at $121{ }^{\circ} \mathrm{C}$ for 15 minutes. The material was then filtered in medium porosity crucibles $(15 \mu \mathrm{m})$ with the aid of a vacuum compressor pump (LT 65 coupled, Limatec, Cruz das Almas, Brazil).

\subsection{FTIR analysis}

Fourier transform infrared (FTIR) spectra of raw and hydrolyzed biomass were analyzed using a spectrometer (FT-IR CARY 630, Santa Clara, USA) to evaluate the changes in the functional groups and the lignocellulosic molecular structure of cupuaçu husks. The spectra ranged from 4000 to $650 \mathrm{~cm}^{-1}$ with $0.4 \mathrm{~nm}$ increments and 32 scans on average.

\subsection{Monomeric sugars quantification}

The main monomer content (glucose, xylose and arabinose) was determined from the liquid fraction of the hydrolysates by High Performance Liquid Chromatography (HPLC) using an Agilent chromatograph, 1260 infinity II (Santa Clara, USA), Supelcogel C-610H chromatographic column (Sigma-Aldrich, St. Luis, USA) and Supelguard C-610H pre-column (Sigma-Aldrich, St. Luis, USA). $\mathrm{H}_{3} \mathrm{PO}_{4}(0.1 \%)$ was used as an eluent at a flow rate of $0.5 \mathrm{~mL} \cdot \mathrm{min}^{-1}$, a temperature of $40{ }^{\circ} \mathrm{C}$ in the oven, and a total running time of 18 minutes. The samples were performed in triplicate, and previously filtered in a $0.22 \mu \mathrm{m}$ polyvinylidene difluoride (PVDF) syringe. The sugar content was calculated according to Santana et al. (2020).

\subsection{High value-added bioproducts content}

The quantification of furanic compounds (FF and HMF) and LA was performed by High Performance Liquid Chromatography (HPLC) using the Shimadzu chromatograph (LC-10 Avp series, Kyoto, Japan), Phenomenex Luna C18 $5 \mu$ column (Torrance, USA) and pre-column Phenomenex C18 (Torrance, USA). A 1: 8 acetronitrile/water solution (at $1 \%$ acetic acid) was used as a mobile phase, at a flow rate of $1 \mathrm{~mL} \cdot \mathrm{min}^{-1}$ and an oven temperature of $30{ }^{\circ} \mathrm{C}$. The yields of these bioproducts were calculated according to Scapin et al. (2020).

\subsection{Pyrolysis (Bio-oil synthesis and characterization)}

The bio-oil was produced by slowly pyrolyzing $30 \mathrm{~g}$ of raw biomass in a Pyrex tube reactor at $450{ }^{\circ} \mathrm{C}$ for 30 minutes (Rambo et al., 2021). The components identified in the bio-oil were identified using a gas chromatography-mass spectrometry analysis (GC-MS) in a GC-EM QP2010 Plus equipment (Shimadzu, Kyoto, Japan) using a capillary column Rtx-5MS WCOT $(30 \mathrm{~m} \times 0.25 \mathrm{~mm} \times 0.25 \mu \mathrm{m})$ and helium $(1.90 \mathrm{~mL} / \mathrm{min})$ as carrier gas. The compounds were identified by comparing their 
mass spectra to data from the National Institute of Standards and Technology (NIST).

\subsection{Economic and energetic potential estimate}

The economic potential of cupuaçu husks was estimated due to the relevance of the commercial viability of lignocellulosic residues in the bio-economic environment (Awasthi et al., 2020). Subsequently, the main components of bio-oil were considered, as well as quantitative yields acquired by hydrolysis of high valueadded by-products (FF, LA, HMF). Additionally, the market value of each product was determined after deducting the costs of acid reagent (hydrolysis) and excluding the costs of electricity and raw biomass (Santana et al., 2020). The theoretical energy potential of bio-oil was calculated in Equation 1 to assess the potential for energy production of cupuaçu husks, as described by Milian-Luperón et al. (2020).

$\mathrm{TEP}=\frac{\mathrm{BWY} * \mathrm{AEV}}{100}$

Where: TEP $=$ Theoretical energy potential, $\mathrm{BWY}=$ Biomass waste yield, and AEV = Average energy value $(\sim 17 \mathrm{MJ} / \mathrm{kg}$ is considered when using bio-oil).

\section{Results and discussion}

\subsection{Biomass chemical characterization and sugars yield}

Figure 1 shows the chemical composition (left) and sugar content (right) of cupuaçu husks (see the chemical composition values in Supplementary Table S1). The holocellulosic fraction, which represents the sum of cellulose and hemicellulose contents in cupuaçu husk (59.6\%), was significantly higher than others raw biomass found in cocoa shell (38.8\%) (Hoyos et al., 2020) and pequi shell (41.6\%) (Scapin et al., 2020), for instance, and similar to the baru mesocarp (59.3\%) found by Rambo et al. (2020). Additionally, complementary methodologies for characterization of alpha-cellulose and hemicellulose (Pedrazzi et al., 2019) of cupuaçu

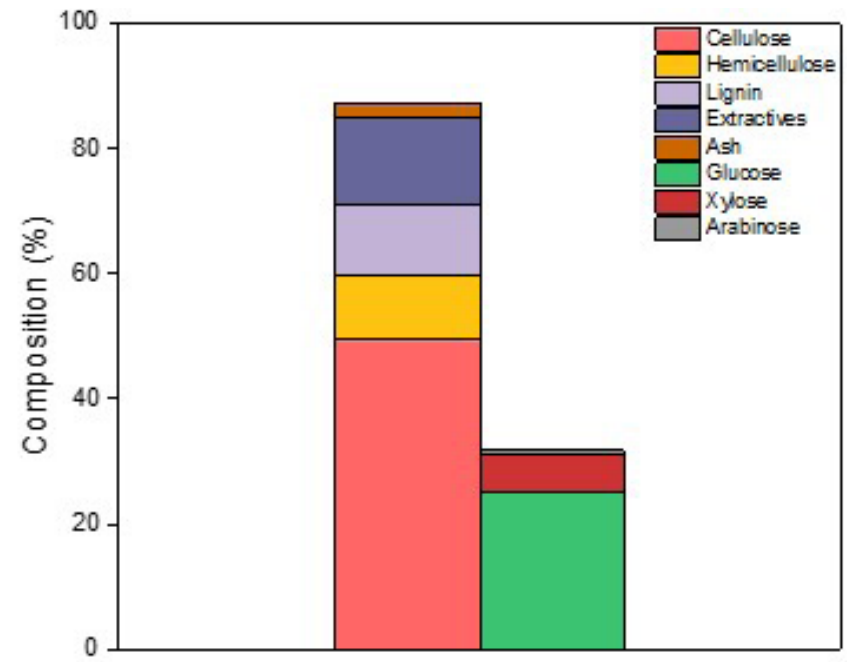

Figure 1. Chemical characterization (left column) and sugar yields (right column) of raw biomass. husks were tested, obtaining a similar result for holocellulose content (58.6\%), corroborating with the reliability of the result.

The total lignin content (11.36\%) was lower than the $17.8 \%$ found in sugar cane bagasse (Guilherme et al., 2015), and close to $11.9 \%$ detected in corncob fibers (Pointner et al., 2014). The low lignin content promotes the use of lignocellulosic materials in biorefineries since it improves biomass digestibility and reduces recalcitrance, enabling bioconversion (Welker et al., 2015). Low levels of extractives ( $<20 \%$ ) facilitate the pyrolysis and acid hydrolysis processes of lignocellulosic materials, reducing solvent consumption and waste generation while lowering production costs (Rambo et al., 2015). The low ash content (2.36\%) favors the thermal transformations of biomass, such as combustion and gasification (Vassilev et al., 2017).

The sugar content obtained from acid hydrolysis of raw biomass demonstrates satisfactory carbohydrate values for the synthesis of biofuels and chemical platforms (Takkellapati et al., 2018). Glucose was found in greater quantity (25\%), followed by xylose (6.16\%) and arabinose (0.57\%). Wijaya et al. (2014) reached maximum values of glucose $(29.9 \%)$ and xylose (16\%) in the hydrolysis of pine wood with sulfuric acid (80\% wt). Borges et al. (2020) obtained approximate values of glucose, xylose and arabinose of $15 \%, 4 \%$, and $1 \%$, respectively, in the hydrolysis of rice husk under the same reaction conditions of this research.

\subsection{Biomass Crystallinity Index}

Crystallinity is a relevant parameter for evaluating its susceptibility to acid hydrolysis and enzymatic digestion, as well as for determining the amount and type of pretreatment required for each biomass (Rambo \& Ferreira, 2015).

The diffractogram of cupuaçu husks is shown in Figure 2. The CrI value of $54.3 \%$ obtained from raw biomass was lower than that found from other biomasses such as cocoa shell (71.4\%) (Hoyos et al., 2020), coconut fiber (60.1\%) (Arsyad et al., 2015), and Brazil nut mesocarp (56\%) (Rambo et al., 2015). This indicates that cupuaçu husks present a lower fraction of

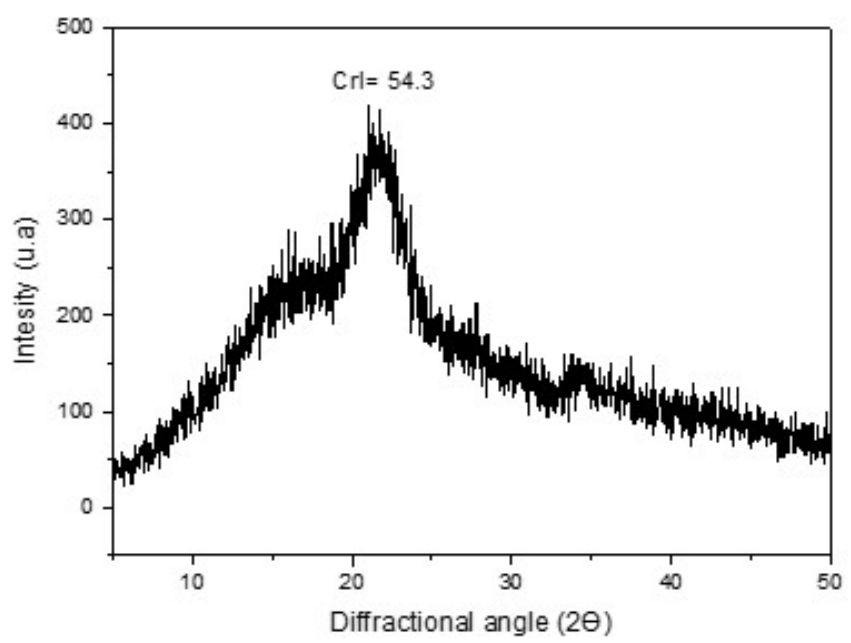

Figure 2. Cupuaçu husks difractogram. 
crystalline cellulose, and, consequently, a greater accessibility to their matrix of carbohydrates necessary for bioconversion processes (Trilokesh \& Uppuluri, 2019).

\subsection{Raw and hydrolyzed biomass spectra}

The FTIR spectrum of raw and hydrolyzed cupuaçu husks is presented in Figure 3. The strong increase in intensity observed in the hydrolyzed biomass spectrum, which forms a peak between the 3500 and $3200 \mathrm{~cm}^{-1}$ regions, indicates an increase in $-\mathrm{OH}$ connections attributed to the formation of carbohydrates (Guilherme et al., 2015). The formation of a peak in the region close to $1641 \mathrm{~cm}^{-1}$ may be related to water absorption during the biomass hydrolysis process (Bekiaris et al., 2015). The strong peaks in the $1100 \mathrm{~cm}^{-1}$ and $1053 \mathrm{~cm}^{-1}$ regions of the hydrolysate are associated with the $\mathrm{C}-\mathrm{O}$ and $\mathrm{C}-\mathrm{O}-\mathrm{C}$ bonds of hemicellulose and crystalline cellulose (Bekiaris et al., 2015; Rambo et al., 2017). The absorption at $850 \mathrm{~cm}^{-1}$ can be attributed to the glycosidic bonds between the sugars (Guilherme et al., 2015). The spectral behavior of the samples confirms that acid hydrolysis contributed to an increase in sugar content (Trilokesh \& Uppuluri, 2019).

\subsection{Hydrolysis and pyrolysis bioproducts}

Figure 4 shows the yield of the main products obtained through pyrolysis (bio-oil) and by-products of acid hydrolysis (FF, LA and HMF) of cupuaçu husks. The dehydration of the pentosan fraction (xylose and arabinose) resulted in a significant production of FF ( $16.1 \%$ or $150 \mathrm{mg} \cdot \mathrm{g}^{-1}$ dry biomass) in the hydrolysate (Matsagar et al., 2017). Świątek et al. (2020) achieved a maximum yield of $18.5 \mathrm{mg} \cdot \mathrm{g}^{-1}$ dry biomass in the hydrolysis of Miscanthus with 0.05 mol.L-1 sulphuric acid at $200{ }^{\circ} \mathrm{C}$. Bariani et al. (2020) obtained a high yield of $64 \%$ in the hydrolysis of rice husks with $1.5 \%$ sulfuric acid (w/w) at $185^{\circ} \mathrm{C}$ and $10 \mathrm{~min}$. of reaction.

The yield of HMF obtained in the hydrolysate was approximately $0.32 \%$ ( $5 \mathrm{mg} \cdot \mathrm{g}^{-1}$ dry biomass). Although HMF is mostly associated with the glucose fraction of the biomass, its low stability makes high yields difficult to acquire (Menegazzo et al., 2018). The yield of LA (4.24\% or $40 \mathrm{mg} \cdot \mathrm{g}^{-1}$ dry biomass) was achieved by decomposing the HMF and rehydrating it in the aqueous medium of the hydrolysate, which explains the low yield of HMF (Liu et al., 2020).

Lu et al. (2012) obtained 7\% yield of LA and 4\% of HMF from glucose using phosphoric acid in a phosphate buffer system under microwave radiation. Scapin et al. (2020) achieved yields of $65 \%, 23.7 \%$ and $3 \%$ of FF, LA and HMF, respectively, in the pequi shell hydrolysate reaction with [BMIM] $[\mathrm{Br}]$. The decreased selectivity of the reactions of FF, LA and HMF synthesis is linked to the lack of specialized catalysts, which are known to reduce the output of by-product formation (Mukherjee et al., 2015). The number of samples and the products yield obtained from acid hydrolysis, as well as their representative chromatograms can be found in Supplementary Table S2, Figures S2 and S3).

The raw biomass bio-oil from cupuaçu husk pyrolysis contains a significant quantity of phenolic organic components (73.9\%). The effects of antioxidant, antibacterial, and anti-inflammatory processes of this chemical class are well-known in medicine.

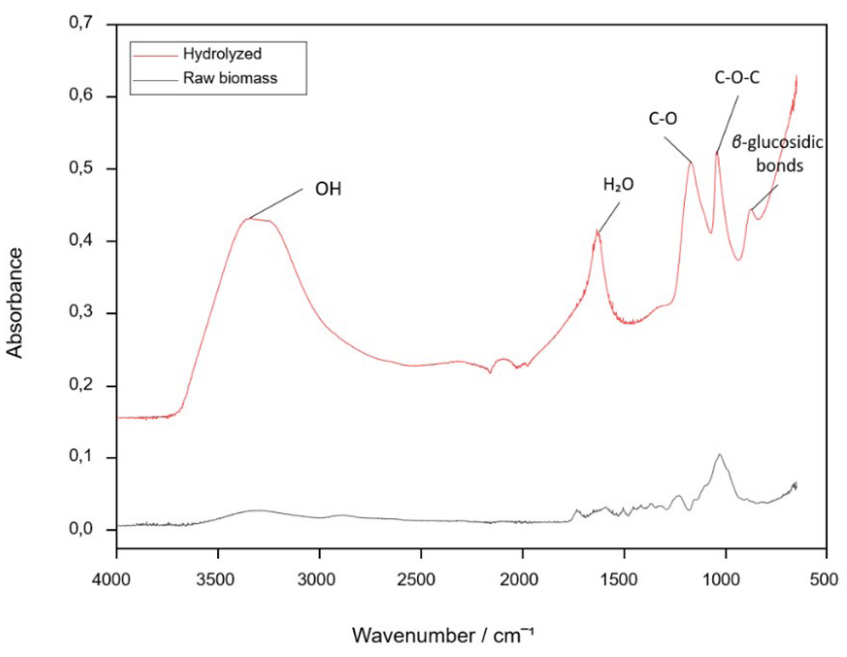

Figure 3. FTIR of raw and hydrolyzed cupuaçu husks.

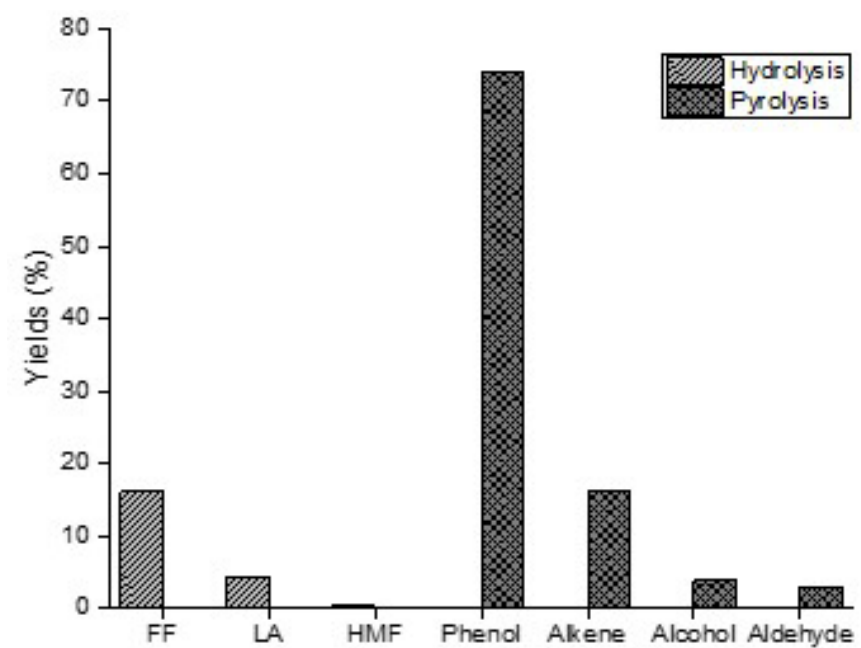

Figure 4. Products obtained from hydrolysis and pyrolysis processes.

Additionally, it is employed in the food, cosmetics, and textile sectors, as well as in the recent synthesis of functional materials (Pessêgo et al., 2011; Albuquerque et al., 2021; Rahim et al., 2019).

Table 1 presents the chemical compounds identified in cupuaçu husks bio-oil by GC-MS (see the Supplementary Figure S4). Squalene was the main compound present in bio-oil (16.1\%), an intermediate metabolite in the biosynthesis of sterols and triterpenes in animals and plants, which is used in medicine for its anti-cancer, antioxidant, detoxifying, hydrating and emollient properties (Hoang et al., 2014; Kim \& Karadeniz, 2012).

The second compound found in great abundance was 2-methoxy-phenol (14.9\%), known as guaiacol. This component is used as a chemical intermediate in the manufacturing of food, cosmetics, perfumery, and cleaning products (Solvay, 2016). It is also used in the production of vanillin, a flavoring agent used in the food and beverage industries (Daugsch \& Pastore, 2005).

The 4-ethyl-2-methoxy-phenol or 4-ethylguaiacol was also found in significant quantities (10.2\%). It is used as a culinary 
flavoring in the production of vanilla, bacon, ham, whiskey, and rums and currently recognized for its anti-inflammatory potential (Zhao et al., 2019).

Brito et al. (2020) verified the predominant presence of vaccenic acid (21.2\%), palmitic acid (19.7\%), and furfural (7\%) compounds in bio-oil derived from pequi residual biomass. Rambo et al. (2021), like this study, identified guaiacol (28.7\%) and creosol (22.5\%) compounds in bio-oil derived from baru hydrolyzed endocarp. Bioproducts observed in this research have a wide range of industrial applications, a high market value, and a suitable use in biorefinery processes (Pessêgo et al., 2011).

\subsection{Approximate economic and energetic analysis}

Table 2 summarizes the market value of the major products obtained through the hydrolysis and pyrolysis of cupuaçu husks. The profit obtained by the hypothesized sale of these products is determined solely by subtracting the cost of the chemical reagent

Table 1. Chemical compounds of cupuaçu husks bio-oil determined by GC-MS analysis.

\begin{tabular}{lcc}
\hline \multicolumn{1}{c}{ Compounds } & $\mathrm{RT}^{\mathrm{a}}$ & Area (\%) \\
\hline Furfural & 4.369 & 3.00 \\
2-Cyclopenten-1-one, 2-methyl- & 6.245 & 1.18 \\
Phenol, 2-methyl- & 11.970 & 1.35 \\
Phenol, 3-methyl- & 12.927 & 1.55 \\
Phenol, 2-methoxy- & 13.242 & 14.90 \\
Phenol, 2,3-dimethyl- & 16.099 & 1.70 \\
Creosol & 17.852 & 5.65 \\
Phenol, 4-ethyl-2-methoxy- & 21.704 & 10.19 \\
2-Methoxy-4-vinylphenol & 23.237 & 8.64 \\
Phenol, 2,6-dimethoxy- & 24.865 & 5.23 \\
Phenol, 2-methoxy-3-(2-propenyl)- & 25.129 & 1.25 \\
Phenol, 2-methoxy-4-propyl & 25.541 & 2.67 \\
Phenol, 2-methoxy-3-(2-propenyl)- & 27.262 & 1.25 \\
Phenol, 2-methoxy-4-(1-propenyl)-, (Z)- & 28.988 & 9.30 \\
5-tert-Butylpyrogallol & 32.113 & 2.21 \\
Phenol, 2,6-dimethoxy-4-(2-propenyl)- & 38.696 & 1.98 \\
Hexanedioic acid, bis(2-ethylhexyl) ester & 60.244 & 2.00 \\
Diisooctyl phthalate & 64.051 & 8.21 \\
6,10,14,18,22-Tetracosapentaen-2-ol, 3-br & 70.617 & 1.62 \\
Squalene & 70.810 & 16.12 \\
\hline
\end{tabular}

${ }^{\mathrm{a}} \mathrm{RT}=$ retention time $(\mathrm{min})$. used in the hydrolysis process $\left(\mathrm{H}_{2} \mathrm{SO}_{4}\right)$. Costs associated with electric energy, water, and raw material were omitted due to the fact that biomass does not yet have a defined market value.

The maximum yield obtained from bio-oil (31.8\%) corresponds to $318 \mathrm{~kg}$ per ton of cupuaçu husks. Of this amount, the main commercialized compounds were considered: Squalene, Guaiacol, 4-Ethylguaiacol, (Z)-2-methoxy-4-(1-propenyl)-Phenol or Isoeugenol, and 2-methoxy-4-vinylphenol or 4-vinylguaiacol, which altogether correspond to more than half of the mass composition of bio-oil.

The income obtained by summing the sales values of the hydrolysis bioproducts to the five primary bio-oil compounds produced from an initial ton of biomass is approximately US $\$ 35,600,496.00$. Guaiacol and 4-Vinylguaiacol represents $96 \%$ of total income in face of their high sale value. It is noteworthy that, in order to get the highest market values, the compounds must be properly isolated through laboratory processes. However, it is notable that cupuaçu husks have a high potential as a raw material for the production of high value-added compounds, as evidenced by a wide range of lignocellulosic residues (Bilal et al., 2017).

In addition to the revenue obtained by the sale of products resulting from the hydrolysis and pyrolysis of cupuaçu husks, energy can be generated through the combustion of bio-oil. Energy production was estimated based on the production of 3,026 tonnes of cupuaçu in 2006 , and knowing that approximately $43 \%$ of its production was related to cupuaçu husks (Instituto Brasileiro de Geografia e Estatística, 2006; Gondim et al., 2001). When considering the bio-oil yield from the husk obtained in this study (31.8\%), the theoretical energy potential reached was approximately $70,342 \mathrm{MJ}$ or 19,541 kWh (Equation 1), enough to supply the consumption of about 117 Brazilian homes for one month (Empresa de Pesquisa Energética, 2020). The conversion of cupuaçu husks into bio-oil supports another key bias in the pyrolysis process: the generation of non-polluting energy from a renewable source, which is currently being targeted as part of the energy sector's efforts to reduce carbon emissions (Climate Action Tracker, 2021).

\section{Conclusions}

The research and characterization of residual biomass are necessary to determine its suitability for biorefinery processes. Acid hydrolysis of cupuaçu husks produced a satisfactory

Table 2. Products income obtained from biomass hydrolysis and pyrolysis.

\begin{tabular}{|c|c|c|c|c|c|}
\hline Process & Bioproducts & Yield (\%) and mass yield ${ }^{a}$ & Approximate market value ${ }^{b}$ & Income $^{c}$ & Reagente Expense $^{\mathrm{d}}$ \\
\hline \multirow[t]{3}{*}{ Hydrolysis } & $\mathrm{FF}$ & $16.13(150000)$ & 4.81 & 721,500 & 99,500 \\
\hline & LA & $4.24(40000)$ & 0.92 & 36,800 & \\
\hline & HMF & $0.32(5000)$ & 66.10 & 330,500 & \\
\hline \multirow[t]{5}{*}{ Pyrolysis } & Guaiacol & $16.12(51,262)$ & 366 & $18,761,892$ & - \\
\hline & Squalene & $13.66(43,439)$ & 5.58 & $242,389.62$ & - \\
\hline & 4-Ethylguaiacol & $9.80(31,164)$ & 1.41 & $43,941.24$ & - \\
\hline & Isoeugenol & $8.51(27,062)$ & 4.92 & $133,145.04$ & - \\
\hline & 4-Vinylguaiacol & $8.21(26,108)$ & 591 & $15,429,828$ & - \\
\hline
\end{tabular}

Total Income/ton of raw biomass $=$ US $\$ 35,600,496.00$

${ }^{\mathrm{a}} \mathrm{g} /$ ton of raw biomass; ${ }^{\mathrm{b} U S} \$ \mathrm{~g}$ of bioproduct; ${ }^{\mathrm{c}}$ maximum market price obtained from Merck (2021); ${ }^{\mathrm{d} U S} \$ /$ ton of raw biomass. 
content of the main carbohydrates (31.7\%) required for the synthesis of biofuels and bioproducts, along with significant amounts of hydrolysis by-products including FF (16.1\%), LA (4.2\%), and HMF (0.3\%), all of which have a high market value in the chemical industry.

Cupuaçu husks bio-oil yield (31.8\%) is consistent with what has been reported in the literature for slow biomass pyrolysis. Among the large number of chemicals detected in bio-oil, the majority (73.9\%) belonged to the phenol class, which is well studied in the fields of medicine, food production, and cosmetics. Apart from its chemical properties, bio-oil has a significant energy potential, making it a promising energy source when it comes to obtaining energy from biomass.

Finally, the estimated income from the commercialization of acid hydrolysis byproducts and the five prevalent compounds found in bio-oil suggest that cupuaçu husks have significant potential as a raw material for high value-added bioproducts. Although the intrinsic aspects of the fruit logistic supply chain must be assessed, this study suggests that cupuaçu husks are a promising source of lignocellulosic biomass for biorefineries, and their utilization represents an environmentally and socially sustainable alternative to the use of agroindustrial waste in Brazil.

\section{Acknowledgements}

We would like to thank the Federal University of Tocantins for the support in carrying out the experiments and the support through the Edital Propesq $N^{\circ} 39 / 2020$, Edital Universal de Pesquisa, CAPES (Coordenação de Aperfeiçoamento de Pessoal de Nível Superior) for the financial support granted, the PPGCiamb (Post Graduate Program in Environmental Sciences) for the support in translation (Edital No 33/2020), the Propesq for the support in publication (Edital No 38/2020) and Federal Institute of Education, Science and Technology of Tocantins (IFTO) for the support through the PAP/inova project no. 47/2020.

\section{References}

Albuquerque, B. R., Heleno, S. A., Oliveira, M. B. P. P., Barros, L., \& Ferreira, I. C. F. R. (2021). Phenolic compounds: current industrial applications, limitations and future challenges. Food \& Function, 12(1), 14-29. http://dx.doi.org/10.1039/D0FO02324H. PMid:33242057.

American Society for Testing and Materials - ASTM. (2018). ASTM D3174-12, standard test method for ash in the analysis sample of coal and coke from coal. U.S.: ASTM International.

Arsyad, M., Wardana, I. N. G., Pratikto, \& Irawan, Y. S. (2015). The morphology of coconut fiber surface under chemical treatment. Matéria, 20(1), 169-177. http://dx.doi.org/10.1590/S1517-707620150001.0017.

Association of Official Analytical Chemists - AOAC. (1995). Methods of analysis of the Association of Official Analytical Chemists (12th ed.). Washington, D.C.: Association of Official Analytical Chemists.

Awasthi, M. K., Sarsaiya, S., Patel, A., Juneja, A., Singh, R. P., Yan, B., Awasthi, S. K., Jain, A., Liu, T., Duan, Y., Pandey, A., Zhang, Z., \& Taherzadeh, M. J. (2020). Refining biomass residues for sustainable energy and bio-products: an assessment of technology, its importance, and strategic applications in circular bio-economy. Renewable \& Sustainable Energy Reviews, 127, 109876. http://dx.doi.org/10.1016/j. rser.2020.109876.
Bariani, M., Boix, E., Cassella, F., \& Cabrera, M. N. (2020). Furfural production from rice husks within a biorefinery framework. Biomass Conversion and Biorefinery, 11, 781-794. http://dx.doi.org/10.1007/ s13399-020-00810-1.

Bekiaris, G., Lindedam, J., Peltre, C., Decker, S. R., Turner, G. B., Magid, J., \& Bruun, S. (2015). Rapid estimation of sugar release from winter wheat straw during bioethanol production using FTIR-photoacoustic spectroscopy. Biotechnology for Biofuels, 8(1), 85. http://dx.doi. org/10.1186/s13068-015-0267-2. PMid:26110018.

Bilal, M., Asgher, M., Iqbal, H., Hu, H., \& Zhang, X. (2017). Biotransformation of lignocellulosic materials into value-added products - a review. International Journal of Biological Macromolecules, 98, 447-458. http://dx.doi.org/10.1016/j.ijbiomac.2017.01.133. PMid:28163129.

Borges, M., Barbosa, R., Rambo, M. K., Rambo, M. C., \& Scapin, E. (2020). Evaluation of residual biomass produced in Cerrado Tocantinense as potential raw biomass for biorefinery. Biomass Conversion and Biorefinery. In press. http://dx.doi.org/10.1007/s13399-020-00892-x.

Brito, M. R., Santana, C. C. Jr., Rambo, M. K. D., Scapin, E., Pedroza, M. M., Rambo, M. C. D., \& Barbosa, L. N. (2020). Utilization of pequi residual biomass from the Brazilian cerrado for obtaining raw and activated biochars and bio-oil. International Journal of Advanced Engineering Research and Science, 7(9), 251-259. http:// dx.doi.org/10.22161/ijaers.79.29.

Climate Action Tracker. (2021). Climate summit momentum: Paris commitments improved warming estimate to $2.4^{\circ} \mathrm{C}$. Retrieved from https://climateactiontracker.org/documents/853/CAT_2021-0504_Briefing_Global-Update_Climate-Summit-Momentum.pdf

Dang, Q., Hu, W., Rover, M., Brown, R. C., \& Wright, M. M. (2016). Economics of biofuels and bioproducts from an integrated pyrolysis biorefinery. Biofuels, Bioproducts \& Biorefining, 10(6), 790-803. http://dx.doi.org/10.1002/bbb.1681.

Daugsch, A., \& Pastore, G. (2005). Obtenção de vanilina: oportunidade biotecnológica. Química Nova, 28(4), 642-645. http://dx.doi. org/10.1590/S0100-40422005000400017.

Ding, T. Y., Hii, S. L., \& Ong, L. (2012). Comparison of pretreatment strategies for conversion of coconut husk fiber to fermentable sugars. BioResources, 7(2), 1540-1547. http://dx.doi.org/10.15376/ biores.7.2.1540-1547.

Dunning, J. W., \& Dallas, D. E. (1949). Analytical procedures for control of saccharification operations. Analytical Chemistry, 21(6), 727-729. http://dx.doi.org/10.1021/ac60030a025.

Empresa de Pesquisa Energética - EPE. (2020). Anuário estatístico de energia elétrica. Retrieved from https://www.epe.gov.br/pt/publicacoesdados-abertos/publicacoes/anuario-estatistico-de-energia-eletrica

Golveia, J. C. S., Santiago, M. F., Sales, P. T. F., Sartoratto, A., Ponezi, A. N., Thomaz, D. V., Gil, E. S., \& Bara, M. T. F. (2018). Cupuaçu (Theobroma grandiflorum) residue and its potential application in the bioremediation of 17-A-ethinylestradiol as a Pycnoporus sanguineus laccase inducer. Preparative Biochemistry \& Biotechnology, 48(6), 541-548. http://dx.doi.org/10.1080/10826068.2018.1466161 . PMid:29939831.

Gondim, T. M S., Thomazini, M. J., Cavalcante, M. J. B., \& Souza, J. M. L. (2001). Aspectos da produção de cupuaçu. Retrieved from https:// www.infoteca.cnptia.embrapa.br/handle/doc/498481

Guilherme, A. A., Dantas, P. V. F., Santos, E. S., Fernandes, F. A. N., \& Macedo, G. R. (2015). Evaluation of composition, characterization and enzymatic hydrolysis of pretreated sugar cane bagasse. Brazilian Journal of Chemical Engineering, 32(1), 23-33. http://dx.doi. org/10.1590/0104-6632.20150321s00003146. 
Gunawan, R., Li, X., Lievens, C., Gholizadeh, M., Chaiwat, W., Hu, X., Mourant, D., Bromly, J., \& Li, C. (2013). Upgrading of bio-oil into advanced biofuels and chemicals. Part I. Transformation of GC-detectable light species during the hydrotreatment of bio-oil using Pd/C catalyst. Fuel, 111, 709-717. http://dx.doi.org/10.1016/j. fuel.2013.04.002.

Hoang, M. H., Ha, N. C., Thom, T., Tam, L. T., Anh, H. T., Thu, N. T., \& Hong, D. D. (2014). Extraction of squalene as value-added product from the residual biomass of Schizochytrium mangrovei PQ6 during biodiesel producing process. Journal of Bioscience and Bioengineering, 118(6), 632-639. http://dx.doi.org/10.1016/j. jbiosc.2014.05.015. PMid:24973317.

Hoyos, C. G., Márquez, P. M., Vélez, L. P., Guerra, A. S., Eceiza, A., Urbina, L., Velásquez-Cock, J., Rojo, P. G., Acosta, L. V., \& Zuluaga, R. (2020). Cocoa shell: an industrial by-product for the preparation of suspensions of holocellulose nanofibers and fat. Cellulose, 27, 10873-10884. http://dx.doi.org/10.1007/s10570-020-03222-6.

Instituto Brasileiro de Geografia e Estatística - IBGE. 2006. Censo agropecuário. Retrieved from https://sidra.ibge.gov.br/tabela/2233

Kawale, H. D., \& Kishore, N. (2019). Bio-oil production from a lignocellulosic biomass and its fuel characteristics. Journal of Physics: Conference Series, 1276(1), 012073. http://dx.doi.org/10.1088/1742$6596 / 1276 / 1 / 012073$.

Kim, S., \& Karadeniz, F. (2012). Biological importance and applications of squalene and squalane. In S. Kim (Ed.), Advances in food and nutrition research (Vol. 65, pp. 223-233). Amsterdam: Academic Press.

Krause, M. C., Moitinho, A. C., Ferreira, L. F. R., Souza, R., Krause, L., \& Caramão, E. (2019). Production and characterization of the bio-oil obtained by the fast pyrolysis of spent coffee grounds of the soluble coffee industry. Journal of the Brazilian Chemical Society, 30(8), 1608-1615. http://dx.doi.org/10.21577/0103-5053.20190059.

Liu, C., Lu, X., Yu, Z., Xiong, J., Bai, H., \& Zhang, R. (2020). Production of levulinic acid from cellulose and cellulosic biomass in different catalytic systems. Catalysts, 10(9), 1006. http://dx.doi.org/10.3390/ catal10091006.

Lu, J., Yan, Y., Zhang, Y., \& Tang, Y. (2012). Microwave-assisted highly efficient transformation of ketose/aldose to 5-hydroxymethylfurfural (5-HMF) in a simple phosphate buffer system. RSC Advances, 2(20), 7652. http://dx.doi.org/10.1039/c2ra21011h.

Matsagar, B. M., Hossain, S. A., Islam, T., Alamri, H. R., Alothman, Z. A., Yamauchi, Y., Dhepe, P. L., \& Wu, K. C. (2017). Direct production of furfural in one-pot fashion from raw biomass using brønsted acidic ionic liquids. Scientific Reports, 7(1), 13508. http://dx.doi. org/10.1038/s41598-017-13946-4. PMid:29044183.

Mendes, F. B., \& Barros, J. H. T. (2021). Bioenergy and bio-based products from the Brazilian Amazon: social, economic, and environmental aspects. In S. I. Ao, A. H. Kim \& M. A. Amouzegar (Eds.), Transactions on engineering technologies (pp. 33-46). Singapore: Springer. http:// dx.doi.org/10.1007/978-981-15-9209-6_3.

Menegazzo, F., Ghedini, E., \& Signoretto, M. (2018). 5-Hydroxymethylfurfural (HMF) production from real biomasses. Molecules, 23(9), 2201. http://dx.doi.org/10.3390/molecules23092201. PMid:30200287.

Merck. (2021). Sigma-Aldrich. Retrieved from https://www.sigmaaldrich. com/US/en

Milian-Luperón, L., Hernández-Rodríguez, M., Falcón-Hernández, J., \& Otero-Calvis, A. (2020). Obtaining bioproducts by slow pyrolysis of coffee and cocoa husks as suitable candidates for being used as soil amendment and source of energy. Revista Colombiana de Química, 49(2), 23-29. http://dx.doi.org/10.15446/rev.colomb. quim.v49n2.83231.
Mohammad, R., Abdul-Sattar, N., Umer, R., \& Raza, N. M. (2019). Editorial: waste biorefineries: future energy, green products and waste treatment. Frontiers in Energy Research, 7, 1-3.

Mukherjee, A., Dumont, M., \& Raghavan, V. (2015). Review: sustainable production of hydroxymethylfurfural and levulinic acid: challenges and opportunities. Biomass and Bioenergy, 72, 143-183. http://dx.doi. org/10.1016/j.biombioe.2014.11.007.

National Renewable Energy Laboratory - NREL. (2008). NREL/TP510-42619: determination of extractives in biomass. Retrieved from https://www.nrel.gov/docs/gen/fy08/42619.pdf

National Renewable Energy Laboratory - NREL. (2012). NREL/TP510-42618: determination of structural carbohydrates and lignin in biomass. Retrieved from https://www.nrel.gov/docs/gen/fy13/42618.pdf

Pedrazzi, C., Dick, G., Coldebella, R., Gentil, M., Giesbrecht, B. M., \& Rosa, R. C. (2019). Química da madeira. Coleção Ciências Rurais, 27, 1-69.

Pessêgo, M., Costa, A. M. R., \& Moreira, J. A. (2011). Importance of phenols structure on their activity as antinitrosating agents: a kinetic study. Journal of Pharmacy \& Bioallied Sciences, 3(1), 128-134. http:// dx.doi.org/10.4103/0975-7406.76491. PMid:21430963.

Pointner, M., Kuttner, P., Obrlik, T., Jäger, A., \& Kahr, H. (2014). Composition of corncobs as a substrate for fermentation of biofuels. Agronomy Research, 12(2), 391-396.

Rahim, A., Kristufek, S. L., Pan, S., Richardson, J. J., \& Caruso, F. (2019). Phenolic building blocks for the assembly of functional materials. Angewandte Chemie International Edition, 58(7), 1904-1927. http:// dx.doi.org/10.1002/anie.201807804. PMid:30221440.

Rambo, M. K. D., \& Ferreira, M. M. C. (2015). Determination of cellulose crystallinity of banana residues using near infrared spectroscopy and multivariate analysis. Journal of the Brazilian Chemical Society, 26(7), 1491-1499. http://dx.doi.org/10.5935/0103-5053.20150118.

Rambo, M. K. D., Alexandre, G., Rambo, M., Alves, A., Garcia, W., \& Baruque, E. (2015). Characterization of biomasses from the north and northeast regions of Brazil for processes in biorefineries. Food Science and Technology, 35(4), 605-611. http://dx.doi.org/10.1590/1678457X.6704.

Rambo, M. K. D., Almeida, K. J. C. R., Rambo, M. C. D., \& Baruque, E. A. Fo. (2017). The response surface methodology as a tool to optimize the extraction and acid hydrolysis processes applied to babaçu residues. Revista Brasileira de Pós-Graduação, 13(32), 807-825.

Rambo, M. K. D., Nemet, Y. K. S., Santana, C. C. Jr., Pedroza, M. M., \& Rambo, M. C. D. (2021). Comparative study of the products from the pyrolysis of raw and hydrolyzed baru wastes. Biomass Conversion and Biorefinery, 11, 1943-1953. http://dx.doi.org/10.1007/s13399019-00585-0.

Rambo, M. K. D., Rambo, M. C. D., Melo, P. M., Oliveira, N. M. L., Nemet, Y. K. S., Scapin, E., Viana, G. C. C., \& Bertuol, D. A. (2020). Sustainability of biorefinery processes based on baru biomass waste. Journal of the Brazilian Chemical Society, 31(2), 273-279. http:// dx.doi.org/10.21577/0103-5053.20190169.

Santana, C. C. Jr., Brito, M. R., Barbosa, L. N., Jaconi, A., Rambo, M. K. D., \& Rambo, M. C. (2020). Environmental-economic assessment of lignocellulosic residual from the legal Amazon for conversion in biochars and bioproducts for biorefineries. International Journal of Advanced Engineering Research and Science, 7(9), 324-337. http:// dx.doi.org/10.22161/ijaers.78.36. [IJAERS]

Scapin, E., Rambo, M. K. D., Viana, G. C. C., Borges, M. S., Rambo, M., \& Carneiro, C. (2020). Production of furanic compounds and organic acids from brazilian pequi (Caryocar Brasiliensis Camb.) residues 
using green chemistry. Journal of the Brazilian Chemical Society, 31(7), 1383-1391. http://dx.doi.org/10.21577/0103-5053.20200023.

Segal, L., Creely, J. J., Martin, A. E. Jr., \& Conrad, C. M. (1959). An empirical method for estimating the degree of crystallinity of native cellulose using the X-Ray diffractometer. Textile Research Journal, 29(10), 786-794. http://dx.doi.org/10.1177/004051755902901003.

Sharma, H. K., Xu, C., \& Qin, W. (2019). Biological pretreatment of lignocellulosic biomass for biofuels and bioproducts: an overview. Waste and Biomass Valorization, 10(2), 235-251. http://dx.doi. org/10.1007/s12649-017-0059-y.

Solvay. (2016). Guaiacol. Retrieved from https://www.solvay.com/en/ product/guaiacol

Świątek, K., Gaag, S., Klier, A., Kruse, A., Sauer, J., \& Steinbach, D. (2020). Acid hydrolysis of lignocellulosic biomass: sugars and furfurals formation. Catalysts, 10(4), 437. http://dx.doi.org/10.3390/ catal10040437.

Takkellapati, S., Li, T., \& Gonzalez, M. (2018). An overview of biorefinery derived platform chemicals from a cellulose and hemicellulose biorefinery. Clean Technologies and Environmental Policy, 20(7), 16151630. http://dx.doi.org/10.1007/s10098-018-1568-5. PMid:30319323.

Trilokesh, C., \& Uppuluri, K. (2019). Isolation and characterization of cellulose nanocrystals from jackfruit peel. Scientific Reports, 9(1), 16709. http://dx.doi.org/10.1038/s41598-019-53412-x. PMid:31723189.
Vassilev, S. V., Vassileva, C. G., Song, Y., Li, W., \& Feng, J. (2017). Ash contents and ash-forming elements of biomass and their significance for solid biofuel combustion. Fuel, 208, 377-409. http://dx.doi. org/10.1016/j.fuel.2017.07.036.

Welker, C., Balasubramanian, V. K., Petti, C., Rai, K., Debolt, S., \& Mendu, V. (2015). Engineering plant biomass lignin content and composition for biofuels and bioproducts. Energies, 8(8), 7654-7676. http://dx.doi.org/10.3390/en8087654.

Wijaya, Y. P., Putra, R. D. D., Widyaya, V. T., Ha, J., Suh, D. J., \& Kim, C. S. (2014). Comparative study on two-step concentrated acid hydrolysis for the extraction of sugars from lignocellulosic biomass. Bioresource Technology, 164, 221-231. http://dx.doi.org/10.1016/j. biortech.2014.04.084. PMid:24859214.

Yan, K., Wu, G., Lafleur, T., \& Jarvis, C. (2014). Production, properties and catalytic hydrogenation of furfural to fuel additives and valueadded chemicals. Renewable \& Sustainable Energy Reviews, 38, 663-676. http://dx.doi.org/10.1016/j.rser.2014.07.003.

Zhao, D., Jiang, Y., Sun, J., Li, H., Luo, X., \& Zhao, M. (2019). Antiinflammatory mechanism Involved in 4-ethylguaiacol-mediated inhibition of LPS-induced inflammation in THP-1 cells. Journal of Agricultural and Food Chemistry, 67(4), 1230-1243. http://dx.doi. org/10.1021/acs.jafc.8b06263. PMid:30614688. 


\section{Supplementary Information}

Supplementary Figure S1. Cupuaçu husks before (left) and after (right) crushed 2.

Supplementary Table S1. Chemical characterization values in raw cupuaçu husks 2.

Supplementary Table S2. Product yields obtained from acid hydrolysis 2 .

Supplementary Figure S2. HPLC chromatogram of furfural and 5-hydroxymethylfurfural obtained from cupuaçu husks acid hydrolysis 3.

Supplementary Figure S3. HPLC chromatogram of levulinic acid obtained from cupuaçu husks acid hydrolysis 3.

Supplementary Figure S4. GC-MS chromatogram of cupuaçu husks bio-oil 3.

This material is available as part of the online article from https://www.scielo.br/j/cta 